\title{
Muscle Architecture and Exercise Performance: A Mini Review
}

\author{
Norkhalid Salimin*, Muhammad Hannan Sazali, MohamadShahrul Azzfar and Ali Nadzalan \\ Faculty of Sports Science and Coaching, Sultan Idris Education University, Malaysia
}

Received: March 27, 2018; Published: April 13, 2018

*Corresponding author: Norkhalid Salimin, Faculty of Sports Science and Coaching, Sultan Idris Education University, Tanjung Malim, Perak, Malaysia,

Email: norkhalid@fsskj.upsi.edu.my

\section{Abstract}

Muscle architecture is the physical arrangement of muscle fibers at the macroscopic level that determines a muscle's mechanical function. Previous studies have shown the existence of relationship between muscle architecture and performance and how training could alter the architecture of muscles (e.g. fascicle length, muscle thickness, pennation angle etc.). Among the types of training that have been investigated was resistance training in which has been shown to cause certain changes in muscle architecture. This mini review aims to briefly discuss how the muscle architecture has been studied in the field of sport/exercise performance.

Keywords: Muscle Architecture; Pennation Angle; Fascicle Length; Muscle Thickness; Exercise

\section{Introduction}

\section{Influence of Muscle Architecture on Performance}

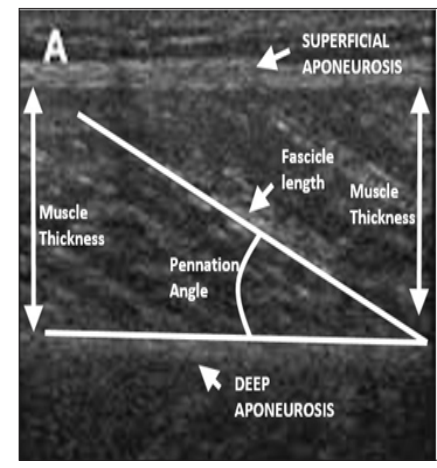

Figure 1: Muscle architecture of vastus lateralis muscle.

The existence of relationship between muscle architecture and performance and how training could alter the architecture of muscles (e.g. fascicle length, muscle thickness, pennation angle etc.) have been shown in several previous studies Blazevich [115], Duclay et al.[13], (Figure 1) showed the muscle architectures of vastuslateralis muscle. Muscle architecture have been found to be associated with running, squat movement and jumping performances Earp et al. [5]; Abe et al. [10], Study by Abe et al. [11] has found that trained sprinters had thicker and longer fascicles, and lesser pennation angles in the VL and the MG and LG compared to trained distance runners. In another study, 100-m sprinters with faster sprint times were shown to have greater muscle thickness at LG and smaller pennation angles at VL, MG, and LG compared to slower runners Kumagai et al. [10].

Contrary to both studies, Earp et al. [16] found greater muscle thickness and pennation along with shorter fascicles were beneficial for jumping ability at increased pre-stretch loads. These results showed greater pennation and shorter fascicles were associated with greater jumping ability at increased pre-stretch loads thus reinforcing the need for training specificity. In line with Earp et al. $[5,7]$, found that lunge performance that was measured by 1RM score increased with greater muscle thickness and pennation angle. These contrast findings suggested that the muscle architectures are different based on the training adopted by the individuals and the exercise or skills performed.

\section{The Effects of Training on Muscle Architecture}

Among the types of training that have been investigated was resistance training in which has been shown to cause certain changes in muscle architecture Duclay et al. [1-4,6,8], Bloomquist et al. [12,13]. As such, study by Nimphius et al. [14] showed strength training cause several changes to muscle architectures including muscle thickness and these changes were related to relative strength and speed improvements among female athletes. Resistance training have been shown to increased pennation angle of muscles that been trained Duclay et al. [1-4,6], Seynnes et al. $[12,13]$. The important of pennation angle couldn't be understood without understanding the basic anatomy of muscle architectures. The divergence in the directionality of fascicles is referred to as 
muscle pennation angle. Fascicles are not like the muscle fibres. Muscle fibres run in parallel within the fascicles. The directionality of the fascicles within the muscle can be highly variable $[15,16]$.

Greater pennation angle allows a greater amount of contractile tissue to attach to a given area of tendon, or aponeurosis, thus increasing the physiological cross-sectional area of a muscle Albracht et al. [17-19]. The increment in pennation angle will causes a cross sectional area of muscle to have more number of fibers. This will therefore increase the muscle ability to produce more force. Manal et al. [20] found pennation angle to be correlated with muscle thickness and improvement in strength. However, an increment of pennation angle with constant cross-sectional area has been observed to cause reduction of strength Ikegawa et al. [21]. This condition was thought to be influenced by the angle of pull of the fibers that is indirect to the pull of the muscle in total, and thus cause the pull of the muscle in total diminished by the cosine of the pennation angle. Fascicle length is the distance of fascicle from aponeurosis to another aponeurosis. Mathematically, it is a product of fascicle thickness and pennation angle. Fascicle length will be increased with the increment of muscle thickness and decrement of pennation angle.

A greater fascicle length was thought to represent either longer sarcomeres or more sarcomeres in series $[1,5,17]$. Sarcomere is the contractile element in the muscles. It has been hypothesized that sarcomeres within longer fascicles will go through relatively less shortening for a given amount of total muscle shortening $[1,10,11,19]$. According to this hypothesis, greater fascicle length would be beneficial when for force production at fast movement speeds. The increment of the length of contractile element will enable faster contraction velocity and more force that can be applied at an increasing velocity. Previous studies have been conducted on the effects of resistance training Bloomquist et al. [12], [22-27], muscle potentiate on Reardon et al. [28], testosterone supplementation $[29,30]$, endurance versus resistance training Farup et al. [31], stretching e Lima, et al. [32] on muscle architecture. Study has also been conducted on the differences of muscle architecture among boys and men Kubo et al. [22,33]. in their study found significant increases in vastuslateralis muscle thickness, fascicle length, 1RM, rate of force development and average force produced among the training group that were assigned to thirteen weeks of resistance training. No significant changes occur to the control group. This finding demonstrated that the muscle architecture adaptations among the training group improved the capacity for developing higher velocities of contraction while in the same time limited the loss of fibre force.

Matta et al. [26] examined the effects of 12 weeks resistance training on muscle pennation angle and muscle thickness in 3 different sites $(50,60$, and $70 \%$ of arm length) of the triceps brachia and biceps brachia among healthy untrained men. Result showed a significant difference was observed between muscle thickness in biceps brachia, with an improvement of $12 \%$ in the proximal site, whereas the distal site increased by only $4.7 \%$. For the long head of the triceps brachia, the muscle thickness and pennation angle at the 3 sites presented significant increases, but no significant variation was observed among them, probably because of the pennated-fiber arrangement. The maximum voluntary contraction (MVC) increased significantly for both muscle groups. The results indicated that the strength training program was efficient in promoting hypertrophy in both muscles, but with dissimilar responses of the pennated and fusiform muscle architecture at different arm sites.

Study has also been conducted on comparing the effects of different exercise on muscle architecture. Malas et al. [25] examined the effects of different exercises on quadriceps muscle strength and structure in persons with knee osteoarthritis. Sixtyone patients with knee osteoarthritis were randomly assigned into 6 exercise groups (isometric right/left, isotonic right/left, isokinetic right/left). Results showed isometric group managed to increased knee extensor strength in both side of leg, muscle thickness and fascicle length on the strengthened side and fascicle length on the contralateral side. The isokinetic group managed to increased muscle thickness in both legs and fascicle length on the contralateral side. In the isotonic group, muscle thickness increased in both side of legs. These findings demonstrated that isometric quadriceps training resulted in bilateral strengthening and that accompanying increase in muscle thickness and fascicle length in the same group was consistent with the strength improvement.

Bourne in their study examined the changes in bicepsfemoris long head (BFLH) fascicle length and hamstring muscle size following 10-weeks of Nordic hamstring exercise or hip extension training. Results showed that compared to baseline, BFLHfascicles were lengthened in the both groups at mid- and post-training and these changes did not differ significantly. BFLH volume increased more for the hip extension than the Nordic hamstring exercise group. It was concluded that both training stimulate significant increases in BFLH fascicle length, however, hip extension training may be more effective for promoting hypertrophy in the BFLH.

\section{Conclusion}

Looking at findings of several previous studies, it can be concluded that muscle architecture would be great to be examined in the future. The findings on the relationship between muscle architecture and performance will be beneficial as this will provide better understanding on the important to develop structural adaptations for performance enhancement.

\section{References}

1. Blazevich AJ (2006) Effects of physical training and detraining, immobilisation, growth and aging on human fascicle geometry. Sports Medicine 36(12): 1003-1017.

2. Blazevich AJ, Cannavan D, Coleman DR, Horne S (2007) Influence of concentric and eccentric resistance training on architectural adaptation in human quadriceps muscles. Journal of Applied Physiology 103(5): 1565-1575.

3. Duclay J, Martin A, Duclay A, Cometti G, Pousson M (2009) Behavior of fascicles and the myotendinous junction of human medial gastrocnemius following eccentric strength training. Muscle \& Nerve 39(6): 819-827.

4. Earp JE (2013) The influence of external loading and speed of movement on muscle-tendon unit behaviour and its implications for training. Edith Cowan University, Perth, Australia.

5. Earp JE, Kraemer WJ, Newton RU, Comstock BA, Fragala MS, et al. (2010) Lower-body muscle structure and its role in jump performance during 
squat, countermovement, and depth drop jumps. The Journal of Strength \& Conditioning Research 24(3): 722-729.

6. Earp JE, Newton RU, Cormie P, Blazevich AJ (2014) The influence of loading intensity on muscle-tendon unit behavior during maximal knee extensor stretch shortening cycle exercise. European Journal of Applied Physiology 114(1): 59-69.

7. Nadzalan AM, Mohamad NI, Lee JLF, Chinnasee C (2016) Relationship between lower body muscle architecture and lunges performance. Journal of Sports Science and Physical Education, Malaysia 5(2): 15-23.

8. Nadzalan AM, Mohamad NI, Lee JLF, Chinnasee C (2017) The effects of step versus jump forward lunge exercise training on muscle architecture among recreational badminton players. World Applied Sciences Journal 35(8): 1581-1587.

9. Nadzalan AM, Mohamad NI, Low JFL, Chinnasee C (2018) Relationship between muscle architecture and badminton-specific physical abilities. Human Movement 19(1): 44-50.

10. Kumagai K, Abe T, Brechue WF, Ryushi T, Takano S, et al. (2000) Sprint performance is related to muscle fascicle length in male 100 -m sprinters. Journal of Applied Physiology 88(3): 811-816.

11. Abe T, Kumagai K, Brechue WF (2000) Fascicle length of leg muscles is greater in sprinters than distance runners. Medicine and Science in Sports and Exercise 32(6): 1125-1129.

12. Bloomquist $\mathrm{K}$, Langberg $\mathrm{H}$, Karlsen $\mathrm{S}$, Madsgaard $\mathrm{S}$, Boesen $\mathrm{M}$, et al (2013) Effect of range of motion in heavy load squatting on muscle and tendon adaptations. European Journal of Applied Physiology 113(8): 2133-2142.

13. Seynnes OR, De Boer M, Narici MV (2007) Early skeletal muscle hypertrophy and architectural changes in response to high-intensity resistance training. Journal of Applied Physiology 102(1): 368-373.

14. Nimphius S, McGuigan MR, Newton RU (2012) Changes in muscle architecture and performance during a competitive season in female softball players. The Journal of Strength \& Conditioning Research 26(10): 2655-2666.

15. Baechle TR, Earle RW (2008) Essentials of strength training and conditioning (Vol. 7): Human kinetics Champaign, IL.

16. Kawakami Y, Ichinose Y, Kubo K, Ito M, Imai M, et al. (2000) Architecture of contracting human muscles and its functional significance. Journal of Applied Biomechanics 16(1): 88-97.

17. Albracht K, Arampatzis A, Baltzopoulos V (2008) Assessment of muscle volume and physiological cross-sectional area of the human triceps surae muscle in vivo. Journal of Biomechanics 41(10): 2211-2218.

18. Bamman MM, Newcomer BR, Larson Meyer DE, Weinsier RL, Hunter GR (2000) Evaluation of the strength-size relationship in vivo using various muscle size indices. Medicine and Science in Sports and Exercise 32(7): 1307-1313.

19. Blazevich AJ, Coleman DR, Horne S, Cannavan D (2009) Anatomical predictors of maximum isometric and concentric knee extensor moment. European Journal of Applied Physiology 105(6): 869-878.
20. Manal K, Roberts DP, Buchanan TS (2006) Optimal pennation angle of the primary ankle plantar and dorsiflexors: variations with sex, contraction intensity, and limb. Journal of Applied Biomechanics 22(4): 255-263.

21. Ikegawa S, Funato K, Tsunoda N, Kanehisa H, Fukunaga T, et al. (2008) Muscle force per cross-sectional area is inversely related with pennation angle in strength trained athletes. The Journal of Strength \& Conditioning Research 22(1): 128-131.

22. Alegre LM, Jiménez F, Gonzalo Orden JM, Martín Acero R, Aguado X (2006) Effects of dynamic resistance training on fascicle lengthand isometric strength. Journal of Sports Sciences 24(5): 501-508.

23. Blazevich AJ, Gill ND, Bronks R, Newton RU (2003) Training-specific muscle architecture adaptation after 5-wk training in athletes. Medicine and Science in Sports and Exercise 35(12): 2013-2022.

24. Kim SY, Ko JB, Farthing JP, Butcher SJ (2014) Investigation of supraspinatus muscle architecture following concentric and eccentric training. Journal of Science and Medicine in Sport 18(4): 378-382.

25. Malas FÜ, Özçakar L, Kaymak B, Ulaşlı A, Güner S, et al. (2013) Effects of different strength training on muscle architecture: clinical and ultrasonographic evaluation in knee osteoarthritis. PM\&R 5(8): 655662.

26. Matta T, Simão R, de Salles BF, Spineti J, Oliveira LF (2011) Strength training's chronic effects on muscle architecture parameters of different arm sites. The Journal of Strength \& Conditioning Research 25(6): 17111717.

27. Scanlon TC, Fragala MS, Stout JR, Emerson NS, Beyer, KS, et al. (2014) Muscle architecture and strength: adaptations to short-term resistance training in older adults. Muscle \& nerve 49(4): 584-592.

28. Reardon D, Hoffman JR, Mangine GT, Wells AJ, Gonzalez AM, et al. (2014) Do changes in muscle architecture affect post-activation potentiation? Journal of Sports Science \& Medicine 13(3): 483-492.

29. Atkinson RA, Srinivas Shankar U, Roberts SA, Connolly MJ, Adams JE, et al. (2010) Effects of testosterone on skeletal muscle architecture in intermediate-frail and frail elderly men. The Journals of Gerontology Series A: Biological Sciences and Medical Sciences 65(11): 1215-1219.

30. Blazevich AJ, Giorgi A (2001) Effect of testosterone administration and weight training on muscle architecture. Medicine and Science in Sports and Exercise 33(10): 1688-1693.

31. Farup J, Kjølhede T, Sørensen H, Dalgas U, Møller AB, et al. (2012) Muscle morphological and strength adaptations to endurance vs. resistance training. The Journal of Strength \& Conditioning Research 26(2): 398407.

32. e Lima KM, Carneiro SP, Alves Dde S, Peixinho CC, de Oliveira LF (2015) Assessment of Muscle Architecture of the Biceps Femoris and Vastus Lateralis by Ultrasound After a Chronic Stretching Program. Clinical Journal of Sport Medicine 25(1): 55-60.

33. Kubo K, Teshima T, Ikebukuro T, Hirose N, Tsunoda N (2014) Tendon properties and muscle architecture for knee extensors and plantar flexors in boys and men. Clinical Biomechanics 29(5): 506-511.

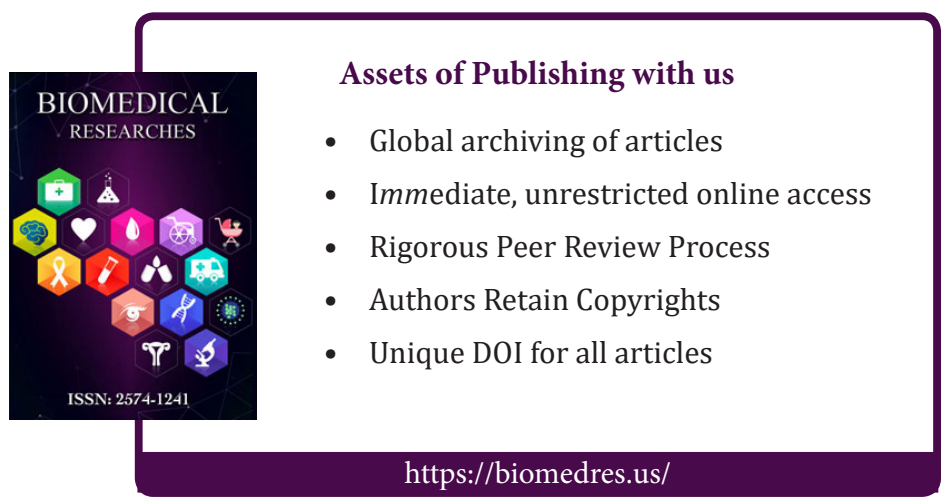

